\title{
MERITOCRACIA ENQUANTO FERRAMENTA DA IDEOLOGIA GERENCIALISTA NA CAPTURA DA SUBJETIVIDADE E INDIVIDUALIZAÇÃO DAS RELAÇÕES DE TRABALHO: UMA REFLEXÃO CRÍTICA
}

\author{
Meritocracy as a tool of managerial ideology in the capture of subjectivity \\ and individualization of labor relations: a critical reflection
}

Alexandre Hochmann Béhar*

\section{RESUMO}

Apresentando-se como uma das palavras de ordem da gestão organizacional contemporânea, a meritocracia tem sua compreensão relacionada ao contexto sócio-histórico e modifica-se através do tempo. Neste sentido, a atual conotação do conceito coincide com transformações ocorridas nas relações de trabalho, nas últimas décadas do século XX. Neste novo contexto, o caráter de dominação ideológica destas flexíveis relações profissionais haveria atuado para o sequestro da subjetividade dos trabalhadores e da precariedade subjetiva, em favor dos interesses organizacionais. Assim, o objetivo deste ensaio teórico é propor uma reflexão crítica sobre o conceito atual da meritocracia enquanto uma ferramenta da ideologia gerencialista, decorrente das transformações nas relações de trabalho nas décadas finais do século passado. Pretende-se, portanto, contribuir para debate a partir de uma perspectiva crítica da ideologia, como alternativa à difundida classificação das dimensões ideológica e afirmativa, possibilitando também ação reflexiva para emancipação individual e transformação da realidade social.

Palavras-chave: Meritocracia; Ideologia gerencialista; Sequestro da subjetividade; Flexibilização das relações de trabalho.

\section{ABSTRACT}

Present as one of the slogans of contemporary organizational management, the understanding related to meritocracy is adjusted to the socio-historical context and changes over time. In this sense, the current understanding of the concept coincides with transformations that occurred in labor relations in the last decades of the twentieth century. However, the character of ideological domination of these flexible professional relations would have acted for the sequestration of the workers' subjectivity and their subjective precariousness, in favor of organizational interests. Thus, the objective of this theoretical essay is to propose a critical reflection on the current understanding of meritocracy as a tool of managerialist ideology, resulting from the transformations in labor relations in the final decades of the last century. It is intended, therefore, to contribute to the debate about the concept from a critical perspective of ideology, as an alternative to the widespread classification of the ideological and affirmative dimensions, also allowing reflexive action for individual emancipation and the transformation of social reality.

Keywords: Meritocracy; Managerialist Ideology; Capture of Subjectivity; Flexibilization of Labor Relations.

\footnotetext{
* Professor de Gestão e Negócios do Instituto Federal de Pernambuco. Mestre em Administração pela Universidade Federal de Pernambuco (UFPE). Doutorando em Administração pela Universidade Federal de Pernambuco (UFPE). E-mail: alexandre.behar@pesqueira.ifpe.edu.br. ORCID: 0000-0002-8354-7866
} 


\section{INTRODUÇÃO}

E ste ensaio teórico tem como objetivo propor uma reflexão crítica da meritocracia no âmbito organizacional contemporâneo. Esta necessidade decorre, principalmente, da dificuldade associada a tal compreensão, além do fato de que, em sua dimensão conceitual mais ampla, "[...] a meritocracia aparece diluída nas discussões sobre desempenho e sua avaliação, justiça social, reforma administrativa e do Estado, neoliberalismo, competência, produtividade, etc. e nunca de forma clara e explícita" (BARBOSA, 2010, p. 21). Tal abrangência conceitual é também identificada no ambiente organizacional. Neste sentido, parece correto destacar que a visão geral sobre a meritocracia associada à gestão organizacional contemporânea se relaciona à dimensão de que

[...] implantar a meritocracia significa estabelecer metas ambiciosas para os funcionários, cobrar resultados e recompensar a realização. Espera-se, com a mudança, vencer a acomodação, reconhecer aqueles que de fato trabalham e fomentar um esforço coletivo para aumentar o desempenho. Livrar-se dos encostados e se ganhar dinheiro. Bom negócio! (WOOD JR, 2014).

A respeito desta perspectiva, Barbosa $(2010$, p. 81) observa que "[...] para a alta administração, a implantação da meritocracia é a solução imaginada para o aumento dos resultados organizacionais e a sobrevivência no mercado". No sentido oposto, estudiosos críticos compreendem que a meritocracia se coloca como uma espécie de ação dominadora, reforçada pelo processo de expansão dos mercados em nível global e aumento da competição organizacional (WOOD JR, 2014). Neste sentido,

[...] ela é vista como desagregadora do ambiente de trabalho, pois estabelece a competição onde ela não existia. Ela é equivocada, pois troca quantidade por qualidade. Ela é injusta, porque não reconhece e retribui o trabalho de todos. Em suma, ela é uma nova forma de exploração e de estresse organizacional (BARBOSA, 2010, p. 83).

Tal contraposição de ideias, entretanto, não significa um desfecho quanto ao debate. A complexificação associada ao conceito de meritocracia reside também no fato de que as compreensões associadas não são imutáveis, tendo sido alteradas ao longo do tempo, de acordo com as condições sócio-históricas. Desta forma, destaco que é a partir do século XVII que a noção contemporânea de meritocracia se desenvolve, apoiada na ascensão de novas configurações políticas e econômicas (principalmente), centradas na sociedade europeia. Tal mudança relaciona-se à ascensão de ideais questionadores da estrutura social medieval, apoiada sobre privilégios relacionados ao nascimento e às relações "de sangue". Em um novo contexto, com a ascensão da classe burguesa, dos ideais lluministas (especialmente associada à noção de liberdade, direito à propriedade e equidade jurídica) e a necessidade de construção de significado das novas relações de poder e produção, a meritocracia se apresentava como meio de legitimação alinhado à ordem social nascente (ARRUDA et al, 2006). Há de se considerar, contudo, que mesmo quando observada no recorte temporal 
relativo ao modo de produção capitalista, são identificadas significativas variações quanto à compreensão do conceito ao longo do tempo (ARRUDA et al, 2006; ALLEN, 2011; 2012).

Sobre tal questão, inicialmente é possível observar orientação do viés tecnicista e cientificista na determinação do mérito, especialmente entre o século XVIII e primeira metade do século XX. A partir da perspectiva de que cada indivíduo traria consigo condições naturais (ou genéticas) próprias e específicas, a mensuração da inteligência e habilidades individuais ocasionaria ordenamento social adequado (BOBBIO; MATTEUCCI; PASQUINO, 1998; ALLEN, 2011). Após este período, no entanto, à noção de mérito verificam-se dimensões de ilimitada liberdade na busca de status social por meio do esforço individual, sob a expectativa de que todo esforço e mérito obtido será recompensado (ALLEN, 2011; 2012).

Assim como em sua compreensão geral, a variação das concepções associadas ao mérito no âmbito das organizações apresenta-se intimamente relacionada ao contexto sócio-histórico. Desta forma, enquanto nas primeiras abordagens teóricas da Administração a caracterização do mérito associava-se à atuação profissional disciplinada, orientada pelas atribuições do cargo ou função exercida pelo indivíduo, previamente estabelecidas pela chefia, de acordo com a estrutura organizacional, (MOTTA, 1986; HARVEY, 1993; ANTUNES, 2000; FARIA, 2015), mais recentemente (especialmente a partir da década de 1970) à noção de mérito associam-se a maior participação e responsabilização dos indivíduos para 0 atingimento dos objetivos organizacionais. Assim, observa-se que flexibilidade tornou-se a palavra de ordem da gestão contemporânea (HARVEY, 1993; ANTUNES, 2000; FARIA; MENEGHETTI, 2007; FARIA, 2015).

Apesar de tais transformações, entretanto, permaneceria preservada a essência de lógicas exploratórias e alienantes praticadas pelas organizações em relação a seus funcionários. Entretanto, neste novo contexto as formas de controle e dominação não se associam principalmente a ações explícitas, destacando-se, ao contrário, "[...] estratégias gerenciais voltadas para o 'sequestro da subjetividade'" (FARIA; MENEGHETTI, 2007, p. 46). A efetivação de tal "sequestro" se dá pelo reconhecimento individual destas construções simbólicas na ação das relações sociais, ou, em outras palavras, na intersubjetividade. Assim, são reforçados o individualismo, representado especialmente pelas possibilidades de ascensão e reconhecimento social, assim como pela lógica da ilimitada capacidade de aprendizagem, realização e comprometimento com a organização e seus símbolos (ALVES, 2014).

Desta maneira, sob um clima de transformação profunda, as novas relações de trabalho que se estabelecem proporcionam o desenvolvimento do que Linhart (2014, p. 45) entende por "precariedade subjetiva", ou seja, aumento dos sentimentos de angústia, insegurança, isolamento e abandono, por parte do trabalhador. Tal precariedade decorre não somente da necessidade de constante adequar e atestar suas capacidades individuais alinhadas às necessidades da organização (presentes e futuras) (LINHART, 2014), mas inclusive na demonstração de atualização e investimento profissional por parte do trabalhador (GAULEJAC, 2014), muitas vezes somente com a finalidade de manter-se empregado (HELAL; ROCHA, 2011). O esforço associado não se refere somente à possibilidade de ascensão profissional ou gratificações extras, mas à própria manutenção do emprego, acentuando o clima de avaliação e competição (LINHART, 2014).

Em diversos aspectos, as observações apresentadas se alinham à perspectiva de Gaulejac (2014) quanto ao nocivo ambiente competitivo e individualista das organizações 
contemporâneas. Neste sentido, a forma como tal captura se dá passa, necessariamente, pela construção e reafirmação de ideologias no ambiente organizacional, notadamente a ideologia gerencialista (GAULEJAC, 2014). Na definição do autor, tal ideologia se apresenta como um sistema de pensamento manipulador, apoiado sob o pretexto da absoluta racionalidade e utilitarismo, mas com efetiva orientação para ilusão e dissimulação de uma lógica de dominação e controle. Por trás de tal ideologia encontra-se a real motivação para tal manobra: "[...] dominação de um sistema econômico que legitima o lucro como finalidade" (GAULEJAC, 2014, p. 69).

A respeito desta questão, parece importante observar a afirmação de Barbosa (2010, p. 21) de que "[...] o termo meritocracia refere-se a uma das mais importantes ideologias e ao principal critério de hierarquização social das sociedades modernas, o qual permeia todas as dimensões de nossa vida social no âmbito do espaço público". Entretanto, ao mesmo tempo em que a meritocracia possuiria ampla aceitação na negação de privilégios pautados na hereditariedade, corporativismo ou ainda na atuação pautada em estereótipos sociais (sua dimensão negativa), tal consenso não é observado no estabelecimento dos meios e das métricas de validação das capacidades e habilidades individuais (sua dimensão afirmativa), para o ordenamento social (BARBOSA, 2010).

Desta forma, compreendo a necessidade para a proposição de uma reflexão crítica quanto ao conceito contemporâneo de meritocracia. Esta relaciona-se ao pressuposto de que a compreensão atual relacionada ao conceito apresentar-se-ia orientada pela ideologia gerencialista, caracterizando-se como representação simbólica das novas relações de trabaIho, especialmente implementadas a partir da década de 1970, fortalecidas não somente na captura da subjetividade, mas também (e inclusive) pela identificação desta construção simbólica intersubjetivamente.

Neste sentido, é importante ressaltar que o desenvolvimento deste ensaio teórico se dá em sentido diverso ao apresentado por Helal (2007). A este respeito, ainda que a proposta aqui presente também seja desenvolver uma reflexão relacionada ao conceito contemporâneo de meritocracia, esta não será realizada a partir do papel da educação formal na concepção de mérito no âmbito social ou organizacional, mas das recentes transformações ocorridas nas relações de trabalho.

Há de se ressaltar ainda que as compreensões relacionadas ao conceito de meritocracia, assim como se modificam com o passar do tempo, também são influenciadas pelas características culturais de uma dada sociedade. Sobre tal aspecto, ainda que tais diferenças tenham sido abordadas por Barbosa (2010) e, mais especificamente a respeito da realidade brasileira, por Barbosa (1996; 2014), destaco que o foco sob o qual se desenvolve este ensaio teórico apoia-se nas características da gestão contemporânea associada às grandes corporações multinacionais. Mesmo considerando que tais organizações guardam diferenças culturais entre si (e mesmo internamente), Pagès et al (2008) e Gaulejac (2014) destacam que é no seio destas organizações que se desenvolvem as novas ações para controle dos funcionários, a partir da década de 1970. Ademais, a compreensão associada a tal recorte analítico decorre do poderio associado a este modelo organizacional que, em virtude das novas práticas competitivas globais, coloca-se em supremacia, difundindo-se para as demais organizações, públicas e privadas, nos diferentes países (GAULEJAC, 2014). 
Desta forma, ressalto que a primeira contribuição deste ensaio teórico é apresentar uma alternativa às dimensões propostas por Barbosa (2010), em virtude do caráter subjetivo da dimensão afirmativa da meritocracia contemporânea. Tal alternativa apoia-se no que Thompson (1990[2009]) define como concepções críticas sobre ideologia, que a consideram um fenômeno manipulador, orientada a partir de interesses de controle. Associado a tal concepção relaciona-se a segunda contribuição deste estudo; a possibilidade de ressignificação dos símbolos que sustentam uma ideologia, contribuindo para reflexão das práticas associadas, possibilitando assim emancipação individual e transformação da realidade social (EAGLETON, 1997; HALL, 2003).

\section{CONTEXTUALIZANDO E CONCEITUANDO IDEOLOGIA}

Conforme observado anteriormente, no intuito de possibilitar a elaboração das contribuições associada a este ensaio teórico, faz-se necessário maior aprofundamento quanto ao próprio conceito de ideologia. Desta maneira, considerando que não há unanimidade quanto a sua compreensão (EAGLETON, 1997; VAN DIJK, 1990), neste trabalho pretendo apresentar as concepções dos principais autores associados à perspectiva crítica sobre ideologia.

Quanto a esta dimensão, é necessário ressaltar a importância da contribuição de Karl Marx (1818-1883), uma vez que este "[...] transformou o conceito, incorporando-a a um marco referencial teórico e a um programa político que eram profundamente dependentes do espírito do lluminismo" (THOMPSON, 1990[2009], p. 43). De forma sucinta, a concepção do autor apoia-se na perspectiva de que a ideologia reforçaria o processo de dominação da classe burguesa sobre o restante da sociedade, por meio da falsa consciência. Assim, fazendo com que a classe dominada tivesse uma falsa consciência sobre realidade em que estão inseridos, supondo serem verdadeiras as condições apresentadas pela ideologia da classe dominante, a burguesia atuaria no controle e manipulação dos indivíduos, inviabilizando sua mobilização e transformação social (THOMPSON, 1990[2009]).

Nota-se, entretanto, que, de forma diferente do proposto por Marx, ao longo do século XX os estudos sobre a ideologia avançaram para concepções apoiadas em dimensões de maior subjetividade e abstração das relações entre indivíduos em sociedade (THOMPSON, 1990[2009]; EAGLETON, 1997; VAN DIJK, 1999; 2006). A este respeito, Thompson (1990[2009], p. 73) destaca as "concepções críticas de ideologia". Estas partem do pressuposto de "[...] que o fenômeno caracterizado como ideologia [...] é enganador, ilusório ou parcial; e a própria caracterização de fenômenos como ideologia carrega consigo um criticismo implícito ou a própria condenação destes fenômenos" (THOMPSON, 1990[2009], p. 73). Assim, neste enfoque "[...] estudar a ideologia é estudar as maneiras como o sentido serve para estabelecer e sustentar relações de dominação" (THOMPSON, 1990[2009], p. 76, grifo do autor). É necessário observar, entretanto, que por dominação, Thompson (1990[2009]) compreende necessariamente a relação entre a classe burguesa e o proletariado.

Também a partir de uma perspectiva crítica de ideologia, Eagleton (1997) amplia a possibilidade de construções ideológicas em sociedade, compreendendo que diferentes grupos sociais desenvolvem ideologias adequadas à sua visão de mundo e convívio coletivo. 
Neste sentido, a sociedade se colocaria como espaço para interação e disputa entre diferentes ideologias, na busca pela predominância sobre as demais.

Cabe ainda destacar o aspecto de representação da ideologia. Neste sentido, Eagleton (1997, p. 29-30) compreende que tais representações se baseiam no "modo como eu 'vivencio' minhas relações com o conjunto da sociedade", ou seja, por meio da significação, por parte dos indivíduos, das relações sociais por eles vivenciadas. Sobre tal questão, Hall (2003, p. 267) observa que

[...] por ideologia eu compreendo os referenciais mentais - linguagens, conceitos, categorias, conjunto de imagens do pensamento e sistemas de representação - que as diferentes classes e grupos sociais empregam para dar sentido, definir, decifrar e tornar inteligível a forma como a sociedade funciona.

Desta forma, apresenta-se crucial destacar o papel do discurso na constituição e compreensão de determinada ideologia. A respeito desta questão Thompson (1990[2009], p.43) destaca que "[...] o termo 'ideologia', rapidamente, tornou-se uma arma numa batalha política, travada no terreno da linguagem". Também Van Dijk (1990) destaca o papel da construção discursiva na expressão e reprodução de uma ideologia, a partir de estruturas discursivas próprias decorrentes da interação e estruturas sociais. Ainda apoiado sob a perspectiva relacional entre discurso e ideologia, Eagleton (1997, p. 22) observa que

[...] a ideologia tem mais a ver com a questão de quem está falando o que, com quem e com que finalidade do que com as propriedades linguísticas inerentes de um pronunciamento", assim o caráter ideológico de um discurso "é uma função da relação de uma elocução com seu contexto social.

Corroborando com tal compreensão, Hall (2003) salienta a relevância em se observar o campo semântico de onde emerge o significado dos signos relativos a uma ideologia. Tal entendimento se dá, necessariamente, a partir de um contexto histórico, um recorte temporal específico, apresentando-se, assim, como peça fundamental para melhor compreensão quanto à representação por signos. Ressalta-se ainda a compreensão de Hall (2003, p. 189), de que

[...] nós experimentamos a ideologia como se ela emanasse de dentro de nós, como se fôssemos seus sujeitos livres, 'funcionando por conta própria'. Na verdade, somos falados ou falam por nós, nos discursos ideológicos que nos aguardam desde o nosso nascimento, dentro dos quais nascemos e encontramos nosso lugar.

No que se refere à relação entre indivíduo e ideologia, faz-se relevante acessar a observação de Eagleton (1997, p. 24) de que, "[...] é certamente difícil acreditar que massas inteiras de seres humanos sustentariam, por um longo período histórico, ideias e crenças que fossem simplesmente absurdas". Neste sentido, cabe destacar a suposição de que, "[...] de modo geral, em razão simplesmente do caráter disseminado e duradouro de tais doutrinas, que elas codificam, ainda que de maneira mistificada, necessidades e 
desejos genuínos" (EAGLETON, 1997, p. 25). Compreende-se, assim, que "a ideologia é uma função da relação de uma elocução com seu contexto social" (EAGLETON, 1997, p. 22), e desta forma a necessidade de debater seus princípios e práticas manipulatórias reside justamente na noção de que

[...] os enunciados ideológicos podem ser verdadeiros em relação à sociedade tal como se encontra constituída no presente, mas falsos na medida em que, desse modo, contribuem para bloquear a possibilidade de transformar um estado de coisas (EAGLETON, 1997, p. 38).

Desta forma, não caberia falar que alguém estaria totalmente desprovido de ação ativa ou elaboração frente a ideologia a que está inserido, ainda que esta influencie de forma manipulatória e ilusória a compreensão individual da realidade. A este respeito, Van Dijk (2006) observa que a aceitação de uma ideologia pelos indivíduos se daria em decorrência não somente da "[...] sua divulgação nos meios de comunicação, o discurso público e os processos sociais de individualização e a concorrência entre os grupos dominados" (VAN DIJK, 2006, p. 232), mas também por diversos mecanismos de manipulação da compreensão destes indivíduos.

É a partir desta compreensão que repousa a possibilidade de emancipação e autonomia individual. Assim, um aspecto fundamental de tal debate apresenta-se na possibilidade de ressignificação dos signos apresentados pela ideologia, especialmente por meio da conscientização. Neste sentido, destaca-se que "[...] a 'crítica' é a forma de discurso que busca habitar internamente a experiência do sujeito a fim de extrair daquela experiência os aspectos 'válidos' que apontam para além de sua situação atual" (EAGLETON, 1997, p. 13). Esta crítica deve buscar proporcionar, necessariamente, conscientização da condição individual atual, proporcionando autonomia para realização de escolhas individuais. De uma perspectiva individual,

[...] significa que, uma vez que se tenham libertado das causas desse sofrimento, devem ser capazes de olhar para trás, reescrever suas histórias de vida e reconhecer que aquilo de que desfrutam agora é o que teriam desejado anteriormente, caso tivessem podido estar conscientes disso (EAGLETON, 1997, p. 14).

Ainda quanto a possibilidade de transformação ou modificação de uma ideologia Hall (2003, p. 193) chama de "luta ideológica", ou mais especificamente

[...] uma cadeia ideológica particular se torna um local de luta não apenas quando as pessoas tentam descolá-la, rompê-la ou contestá-la, suplantando-a por um conjunto inteiramente novo de termos, mas também quando interrompem o campo ideológico e tentam transformar seus significados pela modificação ou rearticulação de suas associações, passando, por exemplo, do negativo para o positivo. Frequentemente, a luta ideológica consiste na tentativa de obter um novo conjunto de significados para um termo ou categoria já existente, de desarticula-lo de seu lugar na estrutura significativa. 
Assim, no que se refere a práticas ideológicas especificamente no ambiente organizacional, a compreensão de que a ação gerencial contemporânea se apresenta como uma ideologia encontra-se fundamentalmente apoiada sobre a necessidade de aumento da acumulação, dos novos ditames do mercado e da competição entre organizações, especialmente a partir das últimas décadas do século passado. Assim, tal constituição ideológica apoia-se especialmente na necessidade de dirimir as contradições existentes neste novo ambiente organizacional, a fim de diminuir (ou anular) a resistência dos trabalhadores, reforçando a conformidade às determinações organizacionais ditas hipermodernas (PAGĖS et al, 2008; GAULEJAC, 2014). Neste sentido, parece importante destacar a compreensão de Gaulejac (2014, p. 69) de que

[...] designar o caráter ideológico da gestão é mostrar que, por trás dos instrumentos, dos procedimentos, dos dispositivos de informação e de comunicação encontram-se em ação certa visão do mundo e um sistema de crenças. A ideologia é um sistema de pensamento que se apresenta como racional, ao passo que mantém uma ilusão e dissimula um projeto de dominação; ilusão da onipotência, do domínio absoluto, da neutralidade das técnicas e da modelação de condutas humanas; dominação de um sistema econômico que legitima o lucro como finalidade.

Assim, a partir de uma perspectiva de competição intensa entre organizações, Gaulejac (2014, p. 31) destaca o gerenciamento enquanto uma tecnologia de poder ${ }^{1}$, voltada ao estabelecimento a mediação entre o capital e o trabalho e "[...] cuja finalidade é obter a adesão dos empregados às exigências da empresa e de seus acionistas". Desta forma, Gaulejac (2014, p. 31) compreende

[...] a gestão como ideologia que legitima uma abordagem instrumental, utilitarista e contábil das relações entre o homem e a sociedade. Sob uma aparência pragmática e racional, a gestão subentende uma representação do mundo que justifica a guerra econômica.

Por consequência, o ambiente de instabilidade e insegurança decorrentes do alto grau de competição vivenciado ocasiona sentimentos de angústia e sofrimento aos indivíduos, em "um sentimento de assédio generalizado" (GAULEJAC, 2014, p. 32). Esta condição possibilita que a ideologia gerencialista se imponha à consciência e crenças individuais, com vistas a um único fim: maior acumulação de capital por parte da organização. Neste ambiente altamente agressivo, a busca por aceitação e aprovação é individualizada e se dá sob regras e procedimentos que, além de não se apresentarem totalmente claros, podem sofrer alterações sem comunicação prévia. Um ilusório sentimento de autonomia na atuação profissional mascara a preferência pela conformidade e homogeneidade, direcionado sempre para atingimento dos melhores resultados (a partir da perspectiva organizacional). Sob tais condições, ainda que aos indivíduos sejam exigidos comportamentos independentes na

1. Por tecnologia de poder pretendo me referir à definição apresentada por Foucault (2004, p. 323), onde 0 mesmo compreende que "[...] determinam a conduta dos indivíduos e os submetem a certos fins ou dominação, objetivando o sujeito". 
resolução (e até antecipação) de problemas, divergências e questionamentos são considerados empecilhos à motivação e realização individual e organizacional (GAULEJAC, 2014).

Entretanto, para melhor caracterização destas transformações sobre a concepção de mérito, faz-se necessário contextualizar as transformações relacionadas ao conceito contemporaneamente.

\section{PRIMEIRAS COMPREENSÕES SOBRE A MERITOCRACIA}

Como já observado, a compreensão relacionada ao conceito atual de meritocracia se relaciona a diversos debates no âmbito da sociedade capitalista, demandando ainda maior aprofundamento e investigação. A partir do exposto, destaco a observação de Barbosa (2010, p. 22) de que, no nível ideológico, a meritocracia se apresentaria "[...] como um conjunto de valores que postula que as posições dos indivíduos na sociedade deve ser consequência do mérito de cada um. Ou seja, do reconhecimento público da qualidade das realizações individuais". A este respeito, Barbosa (2010) apresenta ainda categorização em duas dimensões: uma negativa e outra afirmativa. Em sua dimensão negativa, a meritocracia se apresenta como valores compartilhados socialmente que rechaçam privilégios associados à hereditariedade ou pertencimento à determinado grupo social. Desta forma, Barbosa (2010, p. 22) observa que, em sua dimensão negativa "a meritocracia não atribui importância às variáveis sociais como origem, posição social, econômica e poder político", no acesso a posições sociais ou direitos. Já a dimensão afirmativa da meritocracia apoia-se fundamentalmente sobre a noção de desempenho dos indivíduos (uma combinação entre talento, habilidades e esforço) para ordenamento social. A complexidade associada a tal dimensão, para o ajustamento social, refere-se a inexistência de modelos unânimes de compreensão sobre o que é mérito, e como mensurá-lo (BARBOSA, 2010). Em outras palavras, a ausência de consenso associado a tal dimensão decorre da existência de

[...] múltiplas interpretações acerca de como avaliar o desempenho, do que realmente entra no seu cômputo, do que sejam talento e esforço, de quais são as origens das desigualdades naturais, da relação entre responsabilidade individual e/ou social e desempenho, da existência de igualdade de oportunidade para todos, da possibilidade concreta de mensuração do desempenho individual, etc (BARBOSA, 2010, p. 22).

Contextualizando historicamente, Arruda et al (2006) observam que, do ponto de vista das sociedades modernas, o sistema meritocrático contemporâneo remonta o intervalo entre os séculos XVII e XIX. Nos referidos séculos, seu desenvolvimento apoia-se fundamentalmente nos ideais democráticos e no liberalismo, inspirado nos princípios Iluministas, representação das aspirações da nascente classe social da burguesia frente a sociedade aristocrática (até então representada pela nobreza). Sobre tal aspecto, a meritocracia possuía representação transformadora, uma vez que "[...] a valorização do esforço e do trabalho individual, [...], desempenhou um papel fundamental para a legitimação da nova ordem" (ARRUDA et al., 2006, p. 71). 
Neste sentido, Bobbio, Matteucci e Pasquino (1998, p.747) observam que, “[...] em geral, por Meritocracia se entende o poder da inteligência que, nas sociedades industriais, estaria substituindo o poder baseado no nascimento ou na riqueza, em virtude da função exercida pela escola". Assim, em um primeiro momento, o entendimento sobre mérito individual na sociedade moderna associa-se primordialmente a aptidões técnico-intelectuais, que apresentar-se-iam apoiadas nos títulos e diplomas adquiridos (BOBBIO; MATTEUCCI; PASQUINO, 1998).

Desta maneira, Allen (2011) observa que a perspectiva mecanicista e o viés de ciências naturais aplicado às ciências sociais, especialmente na segunda metade do século XIX e primeira metade do século XX, ocasionaram preponderante foco na mensuração da inteligência individual e especulações quanto ao caráter genético das habilidades humanas. Tais esforços consistiam na tentativa de estabelecer um ordenamento social perfeito, considerando que, sendo a competição individual aleatória e danosa para a sociedade em geral, os indivíduos deveriam ser alocados em funções sociais relacionadas à sua maior habilidade intelectual, proporcionando maior eficiência produtiva possível, ou, como observa Allen (2011, p. 5, tradução livre), "onde as desigualdades são precisamente combinadas às habilidades", visando a estabilidade social.

Associada a esta perspectiva, no âmbito das teorias e práticas organizacionais já é identificável, desde os trabalhos da Administração Científica (TAYLOR, 1990), a preocupação no estabelecimento do mérito. A respeito desta Escola, a preocupação com formas de identificar e recompensar trabalhadores, a partir de incrementos associados à eficiência produtiva, é claramente identificada nos trabalhos de Taylor (1990). Fortemente apoiado sobre a oferta de benefícios financeiros aos funcionários, a compreensão positiva relacionada ao mérito, neste momento, associa-se à realização das atividades e procedimentos da forma como foram definidos pelos gestores organizacionais. Em outras palavras, inseridos sob uma estrutura burocrática rigidamente estabelecida, a adequada atuação para atingimento do mérito associava-se necessariamente à noção de disciplina (MOTTA, 1986; FARIA, 2015).

O desenvolvimento da Escola de Relações Humanas mantém a condição subordinada dos funcionários organizacionais às determinações do nível estratégico da organização, ao menos do ponto de vista de avaliação e validação do mérito. No que se refere ao trabalho de Elton Mayo, Faria (2015, p. 72) compreende a intenção de desenvolvimento de um modelo de sociedade "[...] na qual cada um saiba o que deve fazer e cumpra seu papel sem necessitar compreender as razões para tanto". A relevância da disciplina neste modelo teórico é ainda destacada pelo autor, na medida em que "[...] a eficiência, pressuposto fundamental da organização burocrática, expressa por Taylor e Fayol, é transformada em cooperação por Mayo" (FARIA, 2015, p. 73).

No entanto, a perspectiva do "indivíduo social", decorrente dos estudos da Escola de Relações Humanas, possibilitou o desenvolvimento de novas compreensões associadas ao mérito no ambiente organizacional. Influenciados pelos estudos de Freud (1856-1939), tais estudiosos avançam para fatores motivacionais que estariam além das necessidades financeiras e sociais dos indivíduos, incorporando uma dimensão subjetiva, associada à concepção de autorrealização. Desta forma, sob uma aparência de autonomia para atuação e participação individual, associada ao desempenho de cada funcionário, subliminarmente se apresenta uma sofisticada estrutura de controle e manipulação direcionada aos interesses 
organizacionais, por meio da ideologia participacionalista (TRAGTENBERG, 2005; FARIA, 2015). A este respeito, a partir do movimento das Relações Humanas "[...] surge a empresa educadora de homens, pois parte-se da noção de que a experiência das responsabilidades do trabalhador tem valor formativo, mas deixa a cargo da empresa e a seus conselheiros agir sobre os que processam a informação" (TRAGTENBERG, 2005, p. 28, grifo do autor). Neste sentido, "[...] a democratização das relações humanas é mais uma tarefa de sedução, substituindo o Príncipe pela maior habilidade de persuasão, ou incorporando a força à palavra" (TRAGTENBERG, 2005, p. 29). De outro modo, a "[...] ideologia participacionista, onde a participação, cujo limite é o conflito, é regulamentada pela administração" (FARIA, 2015, p. 74).

Uma terceira concepção relacionada ao mérito nos Estudos Organizacionais relaciona-se à proposta da administração por objetivos, concebida por Peter Drucker (19092005), reforçada posteriormente por uma corrente teórica apoiada sob uma perspectiva pragmática (FARIA, 2015). No que se refere a tal proposta, Faria (2015, p. 93) observa que "[...] o desempenho econômico aparece como prioritário na atuação do administrador, já que a existência e a autoridade da administração só podem ser justificadas pelos resultados econômicos que esta venha a produzir". A respeito desta transformação, a principal mudança proposta refere-se à substituição da "administração através da dominação pela administração através do autocontrole" (FARIA, 2015, p. 96, grifo do autor). Sob tal aspecto, à administração cabe proporcionar "[...] as informações que o trabalhador necessita para ter condições de controlar, avaliar e dirigir seu próprio desempenho" (FARIA, 2015, p. 99, grifo do autor). Assim, por meio da substituição de controles explícitos por controles implícitos, encobertos sob uma aparente ausência de coerção, a autonomia é orientada pelos objetivos de desempenho organizacionais. Em outras palavras, quanto ao reconhecimento do mérito, "[...] seu desempenho ótimo está ligado ao fato de ele enxergar a empresa como se fosse um administrador responsável pelo sucesso e sobrevivência da organização" (FARIA, 2015, p. 99, grifo do autor).

O reforço quanto a estas novas compreensões organizacionais e econômicas (inserido entre estas o conceito de mérito) associa-se necessariamente a transformações políticas e sociais mais amplas. A este respeito, deve ser destacada a crise do Estado de Bem-Estar Social e a ascensão da ideologia neoliberal, especialmente entre as décadas de 1950 a 1970. Em outras palavras, refiro-me à substituição do projeto político, econômico e social apoiado sobre o controle e orientação do Estado por um modelo alinhado aos interesses e necessidades de acumulação do capital e das grandes corporações (especialmente), apoiadas sobre o ideal do livre mercado (FIORI, 1997; VICENTE, 2009). Tendo como discurso prioritário a incapacidade e inabilidade do Estado em tomar as medidas necessárias para dirimir a crise de acumulação, vivenciada nos países capitalistas desde o final da década de 1960, os ideólogos do neoliberalismo defendiam o desmantelamento do intervencionismo estatal (característica do Estado de Bem-Estar Social), especialmente no que se refere às políticas econômicas e sociais (VICENTE, 2009).

Parte desta mudança, a nova compreensão quanto à prática meritocrática, responsabilizando o indivíduo por suas ações, aprendizados, resultados e consequente ascensão social, apoiar-se-ia a partir de agora em novos pilares. Estes associaram-se, fundamentalmente, à (1) diminuição da intervenção externa no estabelecimento de padrões e medições de inteligência e capacidades, basicamente em decorrência da nova compreensão sobre a 
capacidade humana, (2) agora entendida como adaptável. Neste sentido, (3) a concorrência entre os indivíduos passa a ser encorajada, reforçando também o estímulo ao posicionamento individual e da ambição pessoal, na medida em que (4) abandona-se a compreensão da perfeita distribuição de capacidades e habilidades entre os indivíduos de uma sociedade, ou, em outras palavras, cada um pode assumir qualquer posição na estrutura social, desde que apresente os méritos para tanto (ALLEN, 2011).

Desta forma, a partir da perspectiva apoiada sobre o ideal do livre mercado, abolição de barreiras para o capital e autonomia na ação individual, a compreensão de risco econômico associada ao Estado de Bem-Estar Social relacionava-se à percepção de excesso de rigidez na delimitação e determinação da ação organizacional (HARVEY, 1993). Sobre tal aspecto, Harvey (1993, p. 135) observa que

[...] havia problemas de rigidez dos investimentos de capital fixo de larga escala e de longo prazo em sistemas de produção em massa que impediam muita flexibilidade de planejamento e presumiam crescimento estável em mercados de consumo invariantes. Havia problemas de rigidez nos mercados, na alocação e nos contratos de trabalho [...].

Desta forma, a opção para solucionar tais impeditivos passava, prioritariamente, pela dissolução da rigidez associada ao modelo adotado até então. Neste sentido, o autor aponta o início do que ele denominou de "acumulação flexível" (HARVEY, 1993, p. 140, grifo do autor), que representaria um confronto direcionado às bases do modelo até então vigente. É a partir destas observações que Harvey (1993), Bihr (1999) e Antunes (2000) compreendem que as transformações relacionadas ao novo modelo apresentar-se-iam apoiadas na flexibilidade de forma ampla, atuando sobre o mercado de trabalho, produção, distribuição e consumo. Estas mudanças transformam profundamente as relações de trabaIho, inserida nestas a compreensão sobre o mérito.

\section{TRANSFORMAÇÕES NAS RELAÇÕES DO TRABALHO E A NOVA COMPREENSÃO SOBRE MERITOCRACIA}

No âmbito organizacional, o impacto das transformações destacadas ao final da última seção se relaciona à constituição de um novo modelo de relacionamento entre organização e empregados. Tal questão refere-se ao impacto das relações de trabalho estabelecidas sobre as limitações para acumulação de capital já identificadas (BIHR, 1999).

Desta forma, é importante observar que tanto as práticas tayloristas quanto fordistas não se apresentavam alinhadas às novas necessidades organizacionais. Em outras palavras, tanto o modelo de racionalização do trabalho voltado para a maximização da "produtividade através do uso das máquinas e intensificação do trabalho" (PAULA, 2002, p. 130), fortemente baseado em "[...] métodos rígidos e mecanismos punitivos para manter a disciplina e obter a obediência dos funcionários" (PAULA, 2002, p. 131), assim como sua complementação com os métodos da Escola de Relações Humanas, o fordismo (PAULA, 2002), não se apresentavam alinhados à necessidade de flexibilidade requerida para o novo contexto (HARVEY, 1993; ANTUNES, 2000; PAULA 2002; FARIA; MENEGHETTI, 2007). 
Em oposição às abordagens percebidas como rígidas, a possibilidade para transformação adaptativa foi identificada nas práticas organizacionais constituídas na empresa Toyota, sendo denominada toyotismo. Uma vez que tal modelo busca maior eficiência produtiva por meio da diminuição do desperdício, suas ações, guiadas pelo comportamento do mercado, são orientadas "[...] para intensificar o trabalho, diminuir tempos mortos, gerenciar com precisão os enfoques e os fluxos de produção, visando aumentar a produtividade do trabalho ou a taxa de exploração" (FARIA, 2015, p. 1; 79-180). Do ponto de vista do trabaIho, além da maior exigência por capacidades e conhecimentos aos trabalhadores, atuando em multifunções (ANTUNES, 2000), tal modelo é marcado especialmente pelo aumento do envolvimento individual dos operários na cadeia produtiva, atuando com autonomia limitada. Associado à exigência de maior comprometimento e disponibilidade para atendimento dos interesses e necessidades organizacionais (FARIA, 2015), sob os "[...] novos processos produtivos e do novo modelo de gestão toyotista, tornou-se possível atribuir ritmos intensos e precários de trabalho sem a total consciência do trabalhador na sua condição de trabalho" (FARIA; MENEGHETTI, 2007, p. 56).

A partir destas observações, compreende-se que a ação para dominação realizada por meio de tal reestruturação produtiva não mais é centrada em ações explícitas. Sobre este aspecto, Antunes (2000, p. 48) já destacava a atuação "[...] no plano ideológico, por meio do culto de um subjetivismo e de um ideário fragmentador que faz apologia ao individualismo exacerbado contra as formas de solidariedade e de atuação coletiva e social". Destaca, ainda, o direcionamento da tecnologia de gestão da força de trabalho em incentivar ações de autonomia, liderança e trabalho em grupo entre os trabalhadores de uma mesma organização (ainda que setorizada), mas que se configura, "[...] em verdade uma participação manipuladora e que preserva, na essência, as condições de trabalho alienado e estranhado" (ANTUNES, 2000, p. 52).

Neste contexto, ganha em importância também o papel ativo dos indivíduos nos resultados organizacionais, uma vez que, sob tal modelo de trabalho, busca-se "[...] mobilizar conhecimento, capacidades, atitudes e valores necessários para que os trabalhadores possam intervir na produção, não apenas produzindo, mas também agregando valor" (ALVES, 2014, p. 61). Assim, a constituição deste novo profissional "[...] utiliza, com intensidade e amplitude, estratégias de subjetivação que implicam a manipulação incisiva da mente e do corpo por conteúdos ocultos e semiocultos das instâncias intrapsíquicas" (ALVES, 2014, p. 68). Sobre tal aspecto, Alves (2014, p. 55) ainda destaca que, "[...] para além dos discursos de gestão, existe a operação real de administrar o intangível, isto é, que não se vê e, portanto, o que remete a valores, expectativas e sonhos". É sob tal contexto que emerge também, por exemplo o conceito de empregabilidade. Associado às transformações nas relações de trabalho do referido período, de forma geral é possível compreender que o estabelecimento de tal conceito se alinha ao aumento da responsabilização dos profissionais por sua atualização e ampliação de competências (conhecimentos e habilidades), positivamente percebidos, desde que úteis aos interesses empresariais (HELAL; ROCHA, 2011). Tais questões colocam os trabalhadores em condição de intensa ansiedade e insegurança, pois "[...] estão permanentemente preocupados com a ideia de nem sempre estar em condições de responder a elas" (LINHART, 2014, p. 45), ocasionando um tipo específico de precarização relacionada ao desempenho das funções de trabalho: a "precariedade subjetiva" (LINHART, 2014 , p. 45). Sobre este conceito a autor destaca que se apresentaria pelo 
[...] sentimento de não estar 'em casa' no trabalho, de não poder se fiar em suas rotinas profissionais, em suas redes, nos saberes e habilidade acumulados graças à experiência ou transmitidos pelos mais antigos; é o sentimento de não dominar seu trabalho e precisar esforçar-se permanentemente para adaptar-se, cumprir os objetivos fixados, não arriscar-se física ou moralmente (no caso de interações com usuários ou cliente). É o sentimento de não ter a quem recorrer em caso de problemas graves no trabalho, nem aos superiores hierárquicos (cada vez mais raros e cada vez menos disponíveis) nem aos coletivos de trabalho, que se esgarçam com a individualização sistemática da gestão dos assalariados e a concorrência entre eles. É o sentimento de isolamento e abandono. É também a perda da autoestima, que está ligada ao sentimento de não dominar totalmente o trabalho, de não estar à altura, de fazer um trabalho ruim, de não estar seguro de assumir seu posto (LINHART, 2014, p. 46).

Sob tais condições, estes trabalhadores "[...] devem dar provas o tempo todo, demonstrar competência e empregabilidade, justificar sua presença, sobretudo por uma lógica comparativa" (LINHART, 2014, p. 51). Estas circunstâncias precárias implicam também na atuação do indivíduo de maneira que seria considerada indevida, errada ou mesmo antiética ou ilegal para corresponder às demandas e cobranças profissionais (LINHART, 2014).

Desta forma, compreende-se que o sofrimento decorrente da relação de trabalho é agora vivenciado isoladamente, uma vez que a responsabilidade pelo desempenho e atingimento dos resultados é transferida e concentrada na atuação de cada funcionário. Neste cenário, os colegas representam uma ameaça, pois são percebidos, no mínimo, como concorrentes. Sobre tais questões "[...] a instrumentalização do outro que daí decorre tem um alto custo psicológico e moral, mesmo que os assalariados consigam ocultá-lo ou negá-lo quando as condições se prestam a isso" (LINHART, 2014, p. 52). Sob tais circunstâncias, observa-se que "[...] a organização toyotista do trabalho capitalista possui uma densidade manipulatória de maior envergadura" (ALVES, 2014, p. 59), destacando-se não apenas a capacidade de realização ou mesmo a competência técnica para esta, mas "[...] sua disposição intelectual-afetiva, sua capacidade de aprendizagem voltada para a cooperação com a lógica instrumental da valorização" (ALVES, 2014, p. 59). A este respeito, destaco a já detalhada crise do Estado de Bem-Estar Social e a ascensão da ideologia neoliberal. À promoção desta nova realidade político-social e a transformação na percepção de mérito verifica-se a responsabilização do indivíduo pelo seu sucesso e consequente ascensão social. Estes se dariam indispensavelmente por meio de suas habilidades, capacidade de adaptação às demandas exigidas, sua ambição pessoal e os resultados associados ao esforço (ALLEN, 2011).

Complementarmente, do ponto de vista de Allen (2012), ocorre uma modificação na expectativa sobre o comportamento dos indivíduos, de disciplinados para motivados. A partir desta nova perspectiva, o autor propõe o entendimento de que a meritocracia se apresentaria como um conjunto de ações para exercício de controle individual. Esta dimensão associa-se à convicção de que não existiriam mais limites para desenvolvimento das capacidades humanas, ocasionando, desta forma, um movimento orientado para o eterno aprimoramento individual, sem qualquer garantia de contrapartida compensatória estabelecida pelo mérito obtido. Ao contrário, o entendimento neste novo contexto sócio-histórico é de que tal recompensa chegaria "naturalmente". Desta forma, observa-se que o 
novo sistema meritocrático reforça a constituição de esperanças e desejos individuais, que passam a ter maior impacto sobre a compreensão da realidade pessoal (ALLEN, 2012). Neste sentido, observa-se que o sistema meritocrático contemporâneo seria apresentado sob características de liberdade e democratização, mas "[...] na prática, o que se viu foi um conjunto de medidas sem eficácia que alijou a maioria da população de uma série de benefícios, fossem eles jurídicos, econômicos ou sociais. Tratava-se, portanto, de apenas uma mudança formal de poder" (ARRUDA et al., 2006, p. 72).

Também a partir deste ponto de vista, Forster e Tsarfati (2005) ressaltam que, apesar da crença da recompensa por mérito, existem outras barreiras sociais que impediriam o estabelecimento desta sociedade ideal. Uma drástica questão associada a tal percepção refere-se ao entendimento de que, uma vez que a sociedade atual se baseia na capacidade individual de aumentar as próprias habilidades e, portanto, seu mérito, tais barreiras sociais seriam percebidas pelas minorias como deficiências pessoais e não como questões sócio-históricas que dificultam seu desenvolvimento. A partir das observações apresentadas, é interessante destacar a compreensão de Allen (2012, p. 15, tradução livre), de que

[...] meritocracia é agora altamente individualizada sob a forma de uma lógica orientadora que condiciona e direciona nossas vidas diárias. Regula muito mais profundamente hoje do que tinha feito antes, buscando guiar movimentos solitários, ao invés de controlar o eventual resultado que nestes movimentos vão entregar. Meritocracia, não é hoje nenhum princípio de Justiça, se realmente já foi. Representa um sistema de coerção que pretende governar-nos através da manipulação das nossas esperanças.

Especificamente retratando o ambiente organizacional, Castillo e Bernard (2010, p. 543, tradução livre) observam que,

[...] os defensores da meritocracia salientam que nos verdadeiros sistemas meritocráticos todos tem chances iguais para avançar e obter recompensas com base em seus próprios méritos e esforços, independentemente do seu sexo, raça, classe ou outros fatores.

Entretanto, Castillo (2008) e Castillo e Bernard (2010) observam a tendência de, ao menos no âmbito das recompensas organizacionais, as práticas de recompensa direcionadas à remuneração não apresentarem a neutralidade prevista pela meritocracia, uma vez que os resultados indicam que mulheres e outras minorias, mesmo atuando em equivalentes condições profissionais e possuindo notas iguais na avaliação de desempenho, recebiam salário inferior ao de homens brancos, num fenômeno identificado por Castillo e Bernard (2010, p. 545) como o "paradoxo da meritocracia". A tese apresentada pelos autores para tal "incoerência" estaria associada à percepção de que, o simples sentimento de imparcialidade, justiça e objetividade, decorrente dos padrões meritocráticos estabelecidos institucionalmente, tornaria os indivíduos menos vigilantes quanto a sua atuação como lideranças, ocasionando, desta forma, maior propensão a expressar seus preconceitos individuais. 
Desta forma, a partir das questões apresentadas é possível identificar destacada influência das transformações nas relações de trabalho, a partir as últimas três décadas do século XX, na concepção de mérito presente atualmente nas organizações.

\section{CONSIDERAÇÕES FINAIS}

O objetivo deste ensaio teórico se manifesta em proporcionar uma reflexão crítica quanto ao conceito de meritocracia. A relevância quanto a esta reflexão não se dá somente pela acentuada importância do conceito no ambiente organizacional contemporâneo (BARBOSA, 2010), mas também em virtude das críticas associadas a tal compreensão, assim como às práticas decorrentes (FORSTER; TSARFATI, 2005; ARRUDA et al, 2006; CASTILLO, 2008; CASTILLO; BERNARD, 2010; ALLEN, 2011; 2012). No que se refere a tais críticas, foi proposto que esta se apresentaria uma ferramenta da ideologia gerencialista, apresentada por Gaulejac (2014), decorrente das transformações ocorridas nas relações de trabalho nas últimas três décadas do século XX.

Para construção do argumento que suporte tal proposição, foram inicialmente contextualizadas as compreensões associadas à perspectiva crítica da ideologia. Assim, além de considerar o caráter ilusório e manipulatório da ideologia, foi ressaltado sua utilização para estabelecimento e sustentação de relações de poder (EAGLETON, 1997), associada a determinado contexto histórico (THOMPSON, [1990]2009; EAGLETON, 1997; HALL, 2003). Apoiada sobre esta concepção, tal atuação apoiar-se-ia necessariamente sob construções simbólicas, com destaque especial para construções discursivas próprias, carregadas de significado relacionado a intenções, orientadas por interesses dos grupos sociais constituintes de uma ideologia (VAN DIJK, 1990; 2006; EAGLETON, 1997; HALL, 2003). É sob tais considerações que se faz relevante relacionar as compreensões apresentadas ao conceito de ideologia gerencialista, apresentado por Gaulejac (2014). Foi observado então que tal concepção ideológica se sustentaria a partir da constituição de um sistema de crenças direcionadas a dissimular a dominação e modelagem do comportamento humano nas organizações. Sob uma aparência absolutamente racional e objetivista estariam encobertas práticas sistêmicas utilitaristas, voltadas primordialmente para o ganho financeiro organizacional, por meio da maior dedicação e esforço de seus trabalhadores (GAULEJAC, 2014).

A partir destas elaborações teóricas, foram apresentadas as compreensões associadas ao conceito contemporâneo de meritocracia. Desta forma, partindo de perspectiva de ordenamento social, com funções adequadas às capacidades individuais, visando uma espécie de equilíbrio social produtivo, a partir de transformações ocorridas nas décadas de 1960 e 1970, a meritocracia passa ser percebida como livre atuação individual. Tal transformação se relaciona também à percepção de autonomia para atingimento dos anseios pessoais, desde que se apresentasse disposição e habilidades para tanto, explorando ao máximo suas capacidades (ALLEN 2011; 2012).

De forma aproximada, no ambiente organizacional as dimensões relacionadas ao mérito passam por transformações ao longo do tempo. Enquanto inicialmente o mérito era associado à atuação disciplinada, proporcionando ordem e harmonia para realização das determinações dos administradores (TAYLOR, 1990; TRAGTENBERG, 2005; FARIA, 2015), a percepção relativa ao mérito se modifica a partir da flexibilização dos processos de 
trabalho, contemporâneas às mudanças citadas anteriormente (ANTUNES, 2000; CASTILLO; BERNARD, 2010; ALVES, 2014; LINHART, 2014).

A partir da proposta de uma perspectiva unicamente ideológica sobre a meritocracia, assim como da adequação sócio-histórica de sua compreensão, destaquei as profundas transformações nas relações de trabalho, ocorridas no mesmo período. Relacionado a tais mudanças observei que, apoiado sob o mantra da flexibilização, são profundamente incentivadas ações direcionadas ao individualismo e autonomia, desde que alinhadas aos interesses e necessidades organizacionais, inclusive na responsabilização dos indivíduos pela própria capacitação profissional. No entanto, o isolamento e alto nível competitivo vivenciado, a impossibilidade de conciliar objetivos pessoais e organizacionais ou mesmo diferentes demandas organizacionais, assim como as constantes incertezas a respeito das rotinas profissionais e manutenção do posto de trabalho, resultaria por gerar conflitos pessoais e a identificação de contradições insolúveis por parte do trabalhador. Como forma de amenizar e suportar tais condições, o sequestro da subjetividade dos trabalhadores se apresenta tanto como uma ação organizacional para controle e orientação dos comportamentos individuais, quanto uma solução, do ponto de vista do trabalhador, diante de tantas incertezas. Assim, neste novo modelo de trabalho o valor individual depende e mantêm-se diretamente associado à capacidade individual de adequação às necessidades organizacionais em constante mudança, orientando sua dedicação para atividades que proporcionem benefícios organizacionais, a partir da perspectiva utilitarista e financeira (ANTUNES, 2000; FARIA; MENEGHETTI, 2007; HELAL; ROCHA, 2011; ALVES, 2014; LINHART, 2014). Complementarmente, foi observado que tal sequestro ou captura da subjetividade apoiar-se-ia necessariamente sob práticas ideológicas, voltadas para alienação e exercício de controle e dominação dos trabalhadores (FARIA; MENEGHETTI, 2007; PAGÈS et al, 2008; ALVES, 2014; GAULEJAC, 2014). Tal perspectiva, desta forma, apresenta-se profundamente relacionada às concepções críticas de ideologia.

Desta forma, as considerações finais deste ensaio teórico apontam para o fato de que a modificação associada ao conceito de meritocracia apresentar-se-ia estreitamente alinhada às novas lógicas vigentes nas relações de trabalho, contemporaneamente associadas à individualização, realização pessoal, demonstração de capacidade pessoal, proporcionando aumento da competição entre os indivíduos na organização. Tais imposições homogeneizantes e direcionadas ao confronto por resultados individuais apresentar-se-iam também como fonte de sofrimento e exercício de controle individual. Além destes aspectos, a necessidade de justificar as inerentes contradições organizacionais sustentaria a constituição de uma ideologia, do ponto de vista das próprias organizações. Esta apoiar-se-ia, não somente sob o sequestro ou captura da subjetividade dos trabalhadores, mas, necessariamente, intersubjetivamente, fazendo com que estes aceitem de bom grado ou a partir de pressões corporativas e sociais as condições impostas e, mais que isso, atuem orientados e balizados por elas, reforçando-as. Na base desta ideologia identifica-se a necessidade primordial de viabilizar melhores resultados financeiros para a organização, mesmo que seja pela manipulação e restrição dos comportamentos e da diversidade humana. Diante deste cenário, a necessidade de identificação e classificação dos trabalhadores, enquanto geradores de resultados apresenta-se profundamente necessária e relevante, pouco importando as condições de desigualdade e injustiça associado à origem ou história individuais. Ainda 
que relacionados à ideologia gerencialista, tais aspectos também podem ser identificados na compreensão atual quanto a meritocracia, assim como das críticas a ela associadas.

Neste sentido, busquei também proporcionar uma alternativa crítica à classificação apresentada por Barbosa (2010), especialmente no que se refere à sua dimensão afirmativa. Assim, com base nas perspectivas teóricas apresentadas, neste artigo buscou-se evidenciar a concepção de que a meritocracia contemporânea, ao menos no âmbito organizacional, se apresenta como representação ideológica para manipulação e exploração dos funcionários. Tal perspectiva se apoia sobre a compreensão de que, uma vez que os parâmetros para a definição e exigência do mérito são estabelecidos independentemente das capacidades individuais (relativo à dimensão afirmativa destacada), a compreensão contemporânea da meritocracia estimularia a competição individual sem limites, impondo aos funcionários responsabilização pelo próprio desempenho profissional e pelos resultados organizacionais, levando assim ao aumento da exploração dos trabalhadores e dos níveis de sofrimento e estresse dos funcionários, em favor dos interesses organizacionais (FARIA; MENEGHETTI, 2007; HELAL; ROCHA, 2011; ALVES, 2014; LINHART, 2014). Corrobora para tal reflexão o fato de não serem levados em consideração barreiras históricas e socioculturais na concepção sobre o mérito, impossibilitando o enquadramento de alguns grupos de indivíduos às premissas estabelecidas pelos interesses organizacionais, levando à errônea percepção de incapacidade pessoal e até mesmo limitações biológicas (FORSTER; TSARFATI, 2005; ARRUDA et al, 2006; CASTILLO; BERNARD, 2010; ALLEN, 2011; 2012). Desta forma, o caráter ideológico da meritocracia se relaciona às concepções críticas da ideologia (THOMPSON, 1990[2009]), uma vez que foram a ela vinculados aspectos de manipulação, dissimulação ou mesmo disfarce das reais intenções da gestão organizacional sobre a atuação dos funcionários.

É importante ressaltar ainda que, uma vez que este artigo não pretende encerrar o debate quanto à meritocracia contemporânea (mesmo a partir de uma perspectiva crítica), existe a necessidade de novas análises teóricas e empíricas para elaboração de tal compreensão e transformação (ou não) de significado. Esta continuidade pode amenizar as limitações do pesquisador quanto às considerações descritas, além de proporcionar também novas percepções e compreensões relacionadas ao tema. Importante destacar também a importância de outras pesquisas que considerem o impacto de diferenças culturais na compreensão apresentada neste ensaio, em especial no que se refere aos aspectos culturais da sociedade brasileira (nacionalmente e mesmo regionalmente).

Assim, a partir destas considerações espera-se proporcionar reflexão e debate quanto ao conceito, possibilitando a construção de novos significados e compreensões. Tal questão associa-se diretamente ao aporte teórico deste trabalho, uma vez que neste ensaio teve-se como premissa que uma transformação na ideologia dominante se constitui a partir da ressignificação dos conceitos operantes do discurso associado à ideologia vigente (EAGLETON, 1997), ou mesmo da contestação, rompimento ou desassociação (HALL, 2003), na busca pela construção de novos saberes e conhecimentos. Espera-se, desta forma, contribuir para os processos de autonomia individual e transformação social. 


\section{REFERÊNCIAS}

ANTUNES, R. O toyotismo e as novas formas de acumulação do capital. In: (org.) Os sentidos do trabalho: ensaio sobre a afirmação e a negação do trabalho. São Paulo: Boitempo, 2000.

ALLEN, A. Michael Young's The Rise of the Meritocracy: a philosophical critique. British Journal of Educational Studies, v. 59, n. 4, p. 367-382, 2011.

. Life without the ' $X$ ' factor: meritocracy past and present. Power and Education, v. 4, n. 1, p. 4-19, 2012.

ALVES, G.A disputa pelo intangível: estratégias gerenciais do capital na era da globalização. In: ANTUNES, R. (org.). Riqueza e miséria do trabalho no Brasil III. São Paulo: Boitempo, 2014.

ARRUDA, J.E.A. de et al. Mérito: de quem? In: SILVA, J. de S. e; BARBOSA, J.L; SOUZA, A.I. (org.). Práticas pedagógicas e a lógicas meritórias nas universidades. Rio de Janeiro: UFRJ, Pró-reitoria de Extensão, 2006.

BARBOSA, L. Meritocracia à brasileira: o que é desempenho no Brasil? Revista do Serviço Público, Brasília, ano 47, v. 120, n. 3, 1996.

. Igualdade e meritocracia: a ética do desempenho nas sociedades modernas. Rio de Janeiro: Editora FGV, 2010.

. Meritocracia e sociedade brasileira. RAE, São Paulo, v. 54, n. 1, p. 80-85, 2014.

$\mathrm{BIHR}, \mathrm{A}$. A ruptura do compromisso fordista. In: BIHR, A. Da grande noite à alternativa (o movimento operário em crise). São Paulo: Boitempo, 1999.

BOBBIO, N.; MATTEUCCI, N.; PASQUINO, G. Dicionário de Política. Brasília: Editora Universidade de Brasília, 1998.

CASTILLO, E. J. Gender, race, and meritocracy in organizational careers. American Journal of Sociology, v. 113, n. 6, p. 1479-1526, 2008.

CASTILLO, E. J.; BENARD, S. The paradox of meritocracy in organizations. Administrative Science Quarterly, v. 55, n. 4, p. 543-576, 2010.

EAGLETON, T. Ideologia. São Paulo: Uneps/Boitempo, 1997.

FARIA, J.H. de. Economia política do poder. Curitiba: Juruá, 2015.

FARIA, J.H. de; MENEGHETTI, F.K. O Sequestro da Subjetividade In: FARIA, J.H. (org.). Análise Crítica das teorias e práticas organizacionais. São Paulo: Atlas, 2007.

FIORI, J.L. Estado de Bem-Estar Social: padrões e crises. PHYSIS: Rev. Saúde Coletiva, Rio de Janeiro, v. 7, n. 2, p.129-147, 1997.

FORSTER, M. D.; TSARFATI, M. The effects of meritocracy beliefs on women's well-being after first-time gender discrimination. Society for Personality and Social Psychology, v. 31, n. 12, p. 1730-1738, 2005.

FOUCAULT, M. Tecnologias de si, 1982. Verve, n. 6, p. 321-360, 2004. 
GAULEJAC, V. Gestão como doença social: ideologia, poder gerencialista e fragmentação social. Aparecida - SP: Ideias \& Letras, 2014.

HALL, S. Da diáspora: identidades e mediações culturais. Belo Horizonte: Editora UFMG, 2003.

HARVEY, D. A transformação político econômica do capitalismo do final do século XX. In: . A condição pós-moderna: uma pesquisa sobre as origens da mudança cultural. São Paulo: Edições Loyola, 1993.

HELAL, D.H. O papel da educação na sociedade e organizações modernas: criticando a meritocracia. REAd, edição 56, v. 13, n. 2, 2007.

HELAL, D.H.; ROCHA, M. O discurso da empregabilidade: o que pensam a academia e o mundo empresarial. Cadernos EBAPE.BR, Rio de Janeiro, v. 9, n. 1, p. 139-154, 2011.

LINHART, D. Modernização e precarização da vida no trabalho. In: ANTUNES, R. (org.). Riqueza e miséria do trabalho no Brasil III. São Paulo: Boitempo: 2014.

MOTTA, F.C.P. Teoria das organizações: evolução e crítica. São Paulo: Pioneira, 1986.

PAGÈS, M. et al. 0 poder das organizações. São Paulo: Atlas, 2008.

PAULA, A.P.P. de. Tragtenberg revisitado: as inexoráveis harmonias administrativas e a burocracia flexível. RAP, Rio de Janeiro, v. 36, n. 1, p. 127-44, 2002.

TAYLOR, F.W. Princípios de administração científica. Atlas: São Paulo, 1990.

THOMPSON, J. Ideologia e cultura moderna. Petrópolis: Vozes, 1990[2009].

TRAGTENBERG, M. Administração, poder e ideologia. São Paulo: Editora UNESP, 2005.

VAN DIJK, T.A. La noticia como discurso: compreensión, estrutura y producción de la información. Madri: Síntesis, 1990.

Ideologia: uma aproximación multidisciplinaria. Barcelona: Gedisa, 2006.

VICENTE, M.M. História e comunicação na ordem internacional [online]. São Paulo: Editora UNESP; Cultura Acadêmica, 2009. cap. 5.

WOOD JR, T. Meritocracia tropical. Carta Capital - Economia. Publicado em: 19 jun 2014. Disponível em: <http://www.cartacapital.com.br/revista/804/meritocracia-tropical-9607. html>. Acesso em: 29 set 2016.

Data de Submissão: 05/10/2016.

Data de Aprovação: 24/08/2017. 